\title{
EFEITO ANTIMICROBIANO DE NANOPARTÍCULAS DE ZnO E TiO 2 FRENTE AS BACTÉRIAS S. AUREUS E E. COLI
}

\author{
L. C. MOHR ${ }^{1}$, A. P. CAPELEZZO ${ }^{1}$, T. RIPPEL ${ }^{2}$, R. Z. TERNUS ${ }^{2}$, F. DALCANTON ${ }^{3}$, M. A. \\ FIORI $^{1,3}$, J. M. M de MELLO ${ }^{1,3}$ \\ ${ }^{1}$ Universidade Comunitária da Região de Chapecó - Unochapecó-SC, Programa de Pós- \\ Graduação em Ciências Ambientais \\ ${ }^{2}$ Universidade Comunitária da Região de Chapecó - Unochapecó-SC, Departamento de \\ Engenharia Química, Área das Ciências Exatas e Ambientais \\ ${ }^{3}$ Universidade Comunitária da Região de Chapecó - Unochapecó-SC, Programa de Pós- \\ Graduação em Tecnologia e Gestão da Inovação \\ E-mail para contato: laura_cmohr@unochapeco.edu.br
}

\begin{abstract}
RESUMO - Infecções ocasionadas por microrganismos patogênicos são um problema de saúde pública que demandam atenção e estudo já há algum tempo. Novos agentes antimicrobianos despertam interesse de estudo, visando o desenvolvimento de materiais que confiram atividade antimicrobiana. Tendo em vista esta problemática, este trabalho tem como objetivo estudar a atividade antimicrobiana de nanopartículas de óxido de zinco (NPs-ZnO) e nanopartículas de dióxido de titânio $\left(\mathrm{NPs}^{\left.-\mathrm{TiO}_{2}\right)}\right.$ frente às bactérias Staphylococcus aureus (S. aureus) e Escherichia coli (E. coli). Para avaliar a atividade antimicrobiana das NPs-ZnO e $\mathrm{NPs}^{-\mathrm{TiO}_{2}}$ realizou-se testes de difusão em meio sólido e Concentração Inibitória Mínima (CIM). Para as NPs-ZnO, o diâmetro médio do halo de inibição foi de $1,1 \pm 0,06 \mathrm{~cm}$ e $0,7 \pm 0,15 \mathrm{~cm}$ para $S$. aureus e $E$. coli, respectivamente. A CIM das NPs-ZnO determinada no presente estudo para inibir S. aureus varia de $391,7 \mu \mathrm{g} \mathrm{mL}^{-1}$ e $783,3 \mu \mathrm{g} \mathrm{mL} \mathrm{m}^{-1}$, enquanto que para $E$. coli não foi possível determinar a CIM em virtude de a solução saturada de NPs-ZnO não ser suficiente para causar

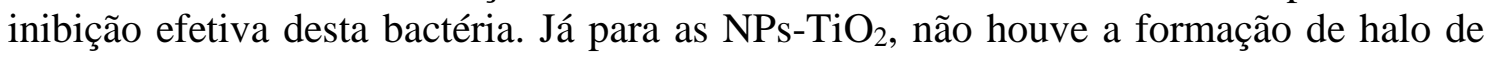
inibição, bem como, não foi possível a determinação da CIM para nenhuma das estirpes bacterianas em estudo, reafirmando a incapacidade de inibição bacteriana das $\mathrm{NPs}^{-\mathrm{TiO}_{2}}$, sem uma fonte fornecedora de luz UV e/ou visível.
\end{abstract}

Palavras-chave: nanopartículas, óxido de zinco, dióxido de titânio, atividade antimicrobiana.

DOI: $10.5965 / 24473650312017011$

\section{INTRODUÇÃO}

As doenças causadas por microrganismos patogênicos representam um problema de saúde pública, que se estende desde o fator social até econômico. O aumento de focos e de infecções 
patogênicas, resistência bacteriana a antibióticos, mutações bacterianas, falta de vacinas adequadas principalmente em países subdesenvolvidos e infecções hospitalares representam perigo para a saúde humana global (SIRELKHATIM et al., 2015).

Um cuidado especial em relação à contaminação por microrganismos é requerido em dispositivos médicos, drogas, superfícies hospitalares, restauração dental e equipamentos cirúrgicos, produtos de saúde e higiene, sistemas de purificação de água, embalagens, alimentos, entre outros (BONILLA, GARCÍA, 2012).

Tendo em vista este cenário, muitas pesquisas vêm sendo realizadas com o intuito de estudar e desenvolver novos agentes antimicrobianos que confiram esta propriedade. Alguns óxidos, tais como óxido de cálcio $(\mathrm{CaO})$, óxido de magnésio $(\mathrm{MgO})$, dióxido de titânio $\left(\mathrm{TiO}_{2}\right)$ e óxido de zinco $(\mathrm{ZnO})$ vem ganhando destaque, revelando-se com potencial atividade antibacteriana mesmo em pequena quantidade, podendo ser substitutos dos agentes convencionais como sal de amônio quaternário e cloro, por exemplo (NAFCHI et al., 2012; OHIRA et al., 2008; SAWAI, 2003).

De acordo com a Food and Drug Administration, o $\mathrm{ZnO}$, é considerado um material seguro e atóxico aos seres humanos. Além disso, a ascensão e fabricação de NPs-ZnO abrem um leque de possibilidades para que as mesmas possam ser incorporadas em diferentes matrizes conferindo propriedades diversas, como capacidade de absorver tanto raios UV-A quanto raios UV-B, propriedade antimicrobiana, melhora de algumas propriedades de empacotamento tais como resistência mecânica, estabilidade e propriedades de barreira (MIRZA et al., 2015; ESPITIA et al., 2012; KUMARI et al., 2011). Dentre os possíveis mecanismos de ação antimicrobiana das NPs$\mathrm{ZnO}$, destacam-se a liberação de íons de zinco $\left(\mathrm{Zn}^{2+}\right)$ e a geração de espécies reativas de oxigênio (DIZAJ et al., 2014, BRAYNER et al., 2006, YAMAMOTO, 2001).

$\mathrm{O}$ dióxido de titânio $\left(\mathrm{TiO}_{2}\right)$ além de apresentar elevada atividade fotocatalítica também possui a propriedade de matar e/ou inibir o crescimento de bactérias. Além disso, apresenta algumas outras vantagens como alta estabilidade, custo relativamente baixo, atóxico (para seres humanos ou ambiente) e possibilidade de ser suportado em vários substratos (SINGH et al., 2013; FU et al., 2005). Sua atividade fotocatalítica e antimicrobiana está associada a propriedades como: obtenção de partículas e/ou compósitos de $\mathrm{TiO}_{2}$ estáveis, geração pares elétron/buraco, estendendo a excitação para além do comprimento de onda UV, mas também região da luz visível e ainda, obtenção de uma reduzida taxa de recombinação do par elétron/buraco recém-criado, pois eles são os responsáveis pela geração de radicais reativos, que atingem as membranas celulares e levam à morte dos microrganismos (FU et al., 2005).

As nanopartículas destes óxidos metálicos estão sendo amplamente estudadas em virtude de resistirem a rigorosas condições de processamento, possuírem elevada área superficial em relação ao volume e apresentarem propriedades químicas e físicas únicas (RAI et al., 2009). Neste trabalho, objetivou-se estudar a atividade antimicrobiana de $\mathrm{NPs}-\mathrm{ZnO}$ e $\mathrm{NPs}^{-\mathrm{TiO}_{2}}$ frente às bactérias Staphylococcus aureus (S. aureus) e Escherichia coli (E. coli).

\section{MATERIAIS E MÉTODOS}

\subsection{Materiais}

As nanopartículas de óxido de zinco (NPs-ZnO), gentilmente cedidas pela Kher Group, possuíam área superficial de $85 \pm 11 \mathrm{~m}^{2} \mathrm{~g}^{-1}$. As $\mathrm{NPs}^{-\mathrm{TiO}_{2}}$, utilizadas constituíram na formulação 
comercial Degussa P25 (70\% anatase e 30\% rutilo) na forma de pó com área superficial de $50 \pm 15 \mathrm{~m}^{2} \mathrm{~g}^{-1}$, sintetizadas pela empresa alemã Evonik Industries, respondendo pelo nome comercial AEROXIDE ${ }^{\circledR}$.

\subsection{Métodos}

\subsubsection{Técnica de difusão em meio sólido a partir de orifício}

A difusão em meio sólido a partir de orifício foi realizada seguindo as recomendações do Clinical and Laboratory Standards Institute (CLSI, 2012a) utilizando-se as bactérias Staphylococcus aureus (ATCC 25923) e Escherichia coli (ATCC 8739). Primeiramente, as suspensões bacterianas foram cultivadas em caldo Brain Heart Infusion (BHI, marca Himedia) por $24 \mathrm{~h}$ a $37 \pm 1{ }^{\circ} \mathrm{C}$ em estufa bacteriológica (marca Quimis, modelo Q316m5). Em seguida, isolou-se as colônias bacterianas e após 24 h estas foram ajustadas em solução salina estéril $(0,85 \%)(\mathrm{NaCl}$, marca Merck) para uma concentração de $10^{8} \mathrm{UFC} \mathrm{mL}^{-1}$ (Unidades Formadoras de Colônia por $\mathrm{mL}$ ) utilizando-se um espectrofotômetro (marca Bel photonics, modelo 1105) no comprimento de onda de $619 \mathrm{~nm}$. Verteu-se meio de cultura Mueller Hinton (marca Merck) nas placas de petri, deixando solidificar. As bactérias em estudo foram semeadas nas placas de petri com o auxilio de um $s w a b$ estéril, realizando-se a semeadura em três direções garantindo a total deposição dos mesmos sobre o meio de cultura. Em cada placa, foram feitos três orifícios equidistantes, com diâmetro de aproximadamente $0,8 \mathrm{~cm}$, sendo depositado nestes NPs-ZnO e NPs-TiO 2 . Incubou-se a $37 \pm 1{ }^{\circ} \mathrm{C}$ por $24 \mathrm{~h}$ e, após decorrido este período, mensurou-se o halo de inibição de crescimento microbiano formado de acordo com a Equação 1.

Halo de inibição= Dex-Din

Onde: Dex: diâmetro externo formado pela ação do agente antimicrobiano sobre os microrganismos $(\mathrm{cm})$ Din: diâmetro ocupado pelo agente antimicrobiano $(\mathrm{cm})$. O ensaio foi realizado em triplicata, sendo considerado como resultado a média do valor dos halos de inibição.

\subsection{Técnica de microdiluição em caldo para a determinação da Concentração Inibitória Mínima (CIM)}

A determinação do CIM foi realizada utilizando-se a metodologia descrita pela Clinical and Laboratory Standards Institute (CLSI, 2012b), com algumas modificações. Foram preparadas soluções padrão nas concentrações de $3133,3 \mu \mathrm{g} \mathrm{mL} \mathrm{m}^{-1}$ para as NPs-ZnO e $9533,3 \mu \mathrm{g} \mathrm{mL}^{-1}$ para as $\mathrm{NPs}^{-\mathrm{TiO}_{2}}$ em água ultrapura, com homogeneização feita através do ultrassom (marca Eco-sonics, modelo Q1.8/40 A). Tais concentrações foram determinadas a partir de testes preliminares de modo que a solução ficasse saturada e os compostos em estudo não precipitassem nos micropoços da placa de análise. Analogamente ao ensaio de difusão em meio sólido as bactérias utilizadas foram Staphylococcus aureus (ATCC 25923) e Escherichia coli (ATCC 8739).

Utilizou-se balões volumétricos de $10 \mathrm{~mL}$ para realização da diluição seriada partindo da solução padrão. Foram realizadas 7 diluições conforme mostra a Tabela 1 . O ensaio foi realizado em microplacas estéreis de 96 micropoços (marca INLAB) com fundo em forma de "U", 
distribuídos em 8 linhas nomeadas de $\mathrm{A}$ até $\mathrm{H}$ e 12 colunas.

Tabela 1 - Soluções com diferentes concentrações de NPs-ZnO e NPs- $\mathrm{TiO}_{2}$ para a determinação da CIM

\begin{tabular}{rcc}
\hline Linha & $\begin{array}{c}\text { Conc. }\left(\mu \mathrm{g} \mathrm{mL}^{-1}\right) \\
\text { NPs-ZnO }\end{array}$ & $\begin{array}{c}\text { Conc. }\left(\mu \mathrm{g} \mathrm{mL}^{-1}\right) \\
\mathrm{NPs}^{-} \mathrm{TiO}_{2}\end{array}$ \\
\hline A & 3133,3 & 9533,3 \\
$\mathrm{~B}$ & 1566,7 & 4766,7 \\
$\mathrm{C}$ & 783,3 & 2883,3 \\
$\mathrm{D}$ & 391,7 & 1191,7 \\
$\mathrm{E}$ & 195,8 & 595,8 \\
$\mathrm{~F}$ & 97,9 & 297,9 \\
$\mathrm{G}$ & 48,9 & 148,9 \\
$\mathrm{H}$ & 24,5 & 74,5 \\
\hline
\end{tabular}

Colocou-se $100 \mu \mathrm{L}$ de caldo BHI em cada um dos micropoços; em seguida, nas colunas 1, 2 e 3 (caracterizadas como a triplicata de análise) e linha A adicionou-se $100 \mu \mathrm{L}$ da solução mais concentrada de NPs-ZnO, diminuindo-a nas linhas posteriores em ordem decrescente. Feito isso, adicionou-se $5 \mu \mathrm{L}$ de suspensão microbiana com $10^{8} \mathrm{UFC} \mathrm{mL}^{-1}$.

Na coluna 6 (controle negativo), foram inseridos $100 \mu \mathrm{L}$ de BHI, $100 \mu \mathrm{L}$ de água ultrapura e $5 \mu \mathrm{L}$ da suspensão bacteriana $\left(10^{8} \mathrm{UFC} \mathrm{mL}^{-1}\right)$, de modo a atestar que a água ultrapura, utilizada como solvente, não estava inibindo o crescimento microbiano.

$\mathrm{Na}$ coluna 9 (controle positivo), foram inseridos $100 \mu \mathrm{L}$ de BHI e $5 \mu \mathrm{L}$ de suspensão bacteriana $\left(10^{8}\right.$ UFC $\left.\mathrm{mL}^{-1}\right)$, de modo a atestar que o caldo utilizado possibilita o crescimento dos microrganismos testados; na coluna 12 , deixou-se somente os $100 \mu \mathrm{L}$ de BHI, de modo a atestar a esterilidade deste (branco). Nas colunas 4, 5, 7, 8,10 e 11 nada foi adicionado.

As microplacas foram então incubadas em estufa microbiológica, sob temperatura de $37 \pm 1{ }^{\circ} \mathrm{C}$ por $20 \mathrm{~h}$. Após decorrido este período, foram adicionados em cada micropoço $20 \mu \mathrm{L}$ de TTC (cloreto de 2,3,5-trifeniltetrazólico, marca Sigma-Aldrich), agente que promove a coloração, possibilitando a visualização do crescimento bacteriano. As microplacas foram levadas para a estufa bacteriológica por mais $4 \mathrm{~h}$, sendo então, retiradas para visualização da coloração. $\mathrm{O}$ mesmo procedimento de análise foi realizado para as $\mathrm{NPs}^{-\mathrm{TiO}_{2}}$.

\section{RESULTADOS E DISCUSSÃO}

\subsection{Técnica de difusão em meio sólido a partir de orifício}

A Figura 1 apresenta o halo médio de inibição para as NPs-ZnO e NPs-TiO ${ }_{2}$ frente a $S$. aureus e E. coli. 

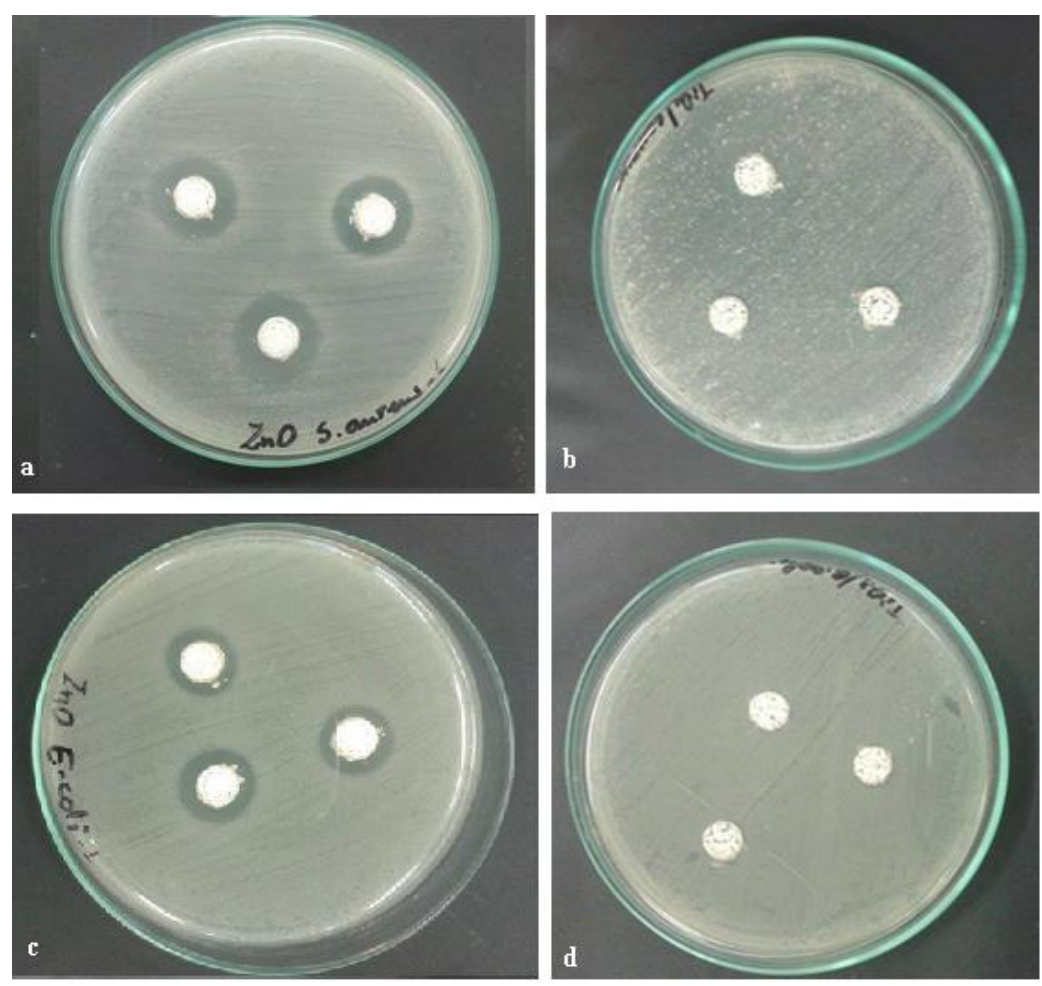

Figura 1 - Resultados do teste de difusão em meio sólido para (a) NPs-ZnO/S. aureus; (b) NPs-

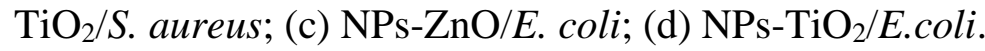

Através da Figura 1(a) e 1(c), pode-se visualizar o halo médio de inibição gerado pelas NPs$\mathrm{ZnO}$ frente a $S$. aureus e E. coli. Quando mensurados, estes foram de $1,1 \pm 0,06 \mathrm{~cm}$ e 0,7 $\pm 0,15$ $\mathrm{cm}$, respectivamente. Analisando-se o tamanho dos halos de inibição gerados pelas NPs-ZnO, é possível verificar que a atividade antimicrobiana é mais intensa contra a bactéria $S$. aureus quando comparado a E. coli. Segundo Bonilla e Gárcia (2012), as células bacterianas gram-positivas, que é o caso do $S$. aureus, possuem apenas uma camada exterior, o que facilita a penetração de moléculas externas, promovendo a interação com a membrana citoplasmática e tornando-as mais frágeis quando comparadas às células bacterianas gram-negativas, como por exemplo, E. coli. Estas, possuem uma membrana adicional com uma estrutura de bicamada fosfolipídica, responsável pela proteção da membrana citoplásmica interior, em maior grau, o que promove maior resistência à essa classe de bactérias.

Padmavathy e Vijayaraghavan (2008) verificaram que o tamanho do diâmetro médio de partícula é um fator preponderante na atividade antimicrobiana de nanopartículas de oxido de zinco frente a E. coli e Quando testadas as NPs-ZnO com tamanho de partícula de $12 \mathrm{~nm}$ o halo de inibição foi de 3,1 $\pm 0,01 \mathrm{~cm}$ e para NPs-ZnO de $45 \mathrm{~nm}$ o halo de inibição foi de 2,7 $\pm 0,01 \mathrm{~cm}$. Narayanan et al. (2012) verificaram que a quantidade de NPs-ZnO é um fator positivo quando testada a atividade antimicrobiana. Os autores utilizaram 20,40,60, 80 e $100 \mu \mathrm{g}$ de pó e obtiveram os seguintes halos de inibição para $S$. aureus $1,8,1,9,2,0,2,0$ e $2,1 \mathrm{~cm}$ e 1,3, 1,4, 1,6, 1,6 e $1,7 \mathrm{~cm}$ para $E$. coli, respectivamente.

Para as $\mathrm{NPs}^{-\mathrm{TiO}_{2}}$ não houve halo de inibição para ambas as bactérias em estudo. Alguns estudos atestam que as $\mathrm{NPs}^{-\mathrm{TiO}_{2}}$ possuem atividade antimicrobiana frente às bactérias gram- 
positivas e gram-negativas em virtude de sua atividade fotocatalítica, estando esta atividade associada aos pares elétron/buraco gerados no processo de fotoexcitação, os quais interagem com a membrana celular dos microrganismos, causando danos à mesma e ocasionando vazamento de minerais, proteínas e materiais genéticos, culminando em morte celular (Bonilla et al., 2013; Fu et al., 2005; Joo et al., 2005). Porém, tal atividade se limita a exposição do composto a luz UV e/ou luz visível, agentes responsáveis por promover a ativação do composto e consequente geração dos pares elétron/buraco. Logo, sem a presença deste agente, as $\mathrm{NPs}_{-} \mathrm{TiO}_{2}$ não apresentam atividade antimicrobiana eficaz, o que é comprovado no presente estudo.

\subsection{Concentração Inibitória Mínima (CIM)}

O estudo da CIM é importante para determinar qual a menor concentração de solução capaz de inibir o crescimento de microrganismos. A Figura 2 mostra os resultados do teste de Concentração Inibitória Mínima para as NPs-ZnO quando testadas frente a $S$. aureus e E. coli, Figura 2(a) e 2(b), respectivamente.

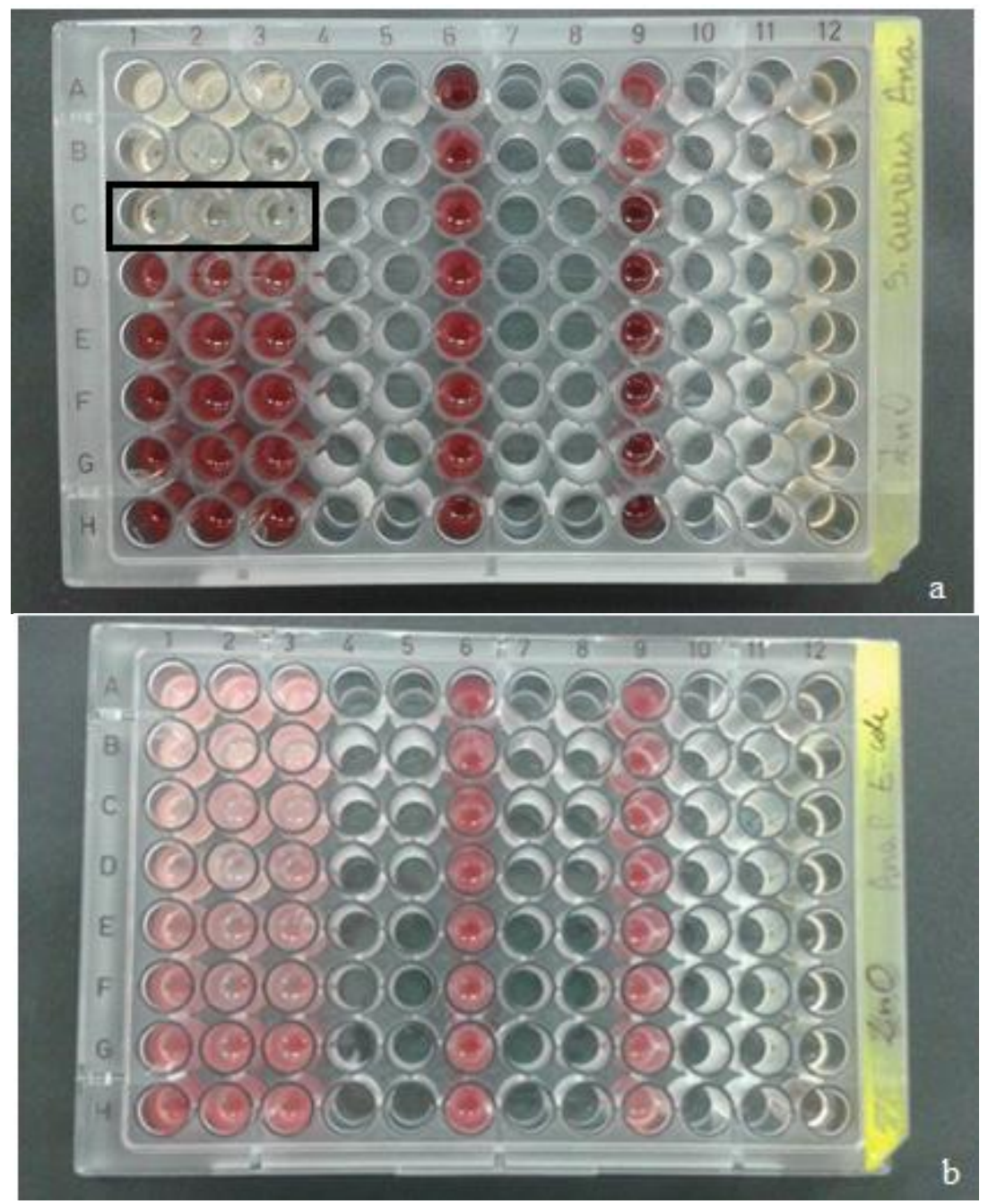


Figura 2 - Resultados do teste de CIM para as NPs-ZnO frente a S. aureus (a) e E. coli (b).

Como pode ser observado na Figura 2(a), a CIM das NPs-ZnO para inibir o crescimento de S. aureus na concentração de $10^{8} \mathrm{UFC} \mathrm{ml}^{-1}$ está entre a Linha C e D, ou seja, entre $391,7 \mu \mathrm{g} \mathrm{mL} \mathrm{m}^{-1}$ e 783,3 $\mu \mathrm{g} \mathrm{mL} \mathrm{mL}^{-1}$. Para a bactéria $E$. coli não observou-se inibição de células microbianas em nenhuma das concentrações estudadas, ou seja, estas foram insuficientes para inibir o crescimento da referida bactéria.

Embora o ensaio de difusão em meio sólido tenha atestado a capacidade bactericida e/ou bacteriostática das NPs-ZnO frente a $E$. coli através do mecanismo de difusão, as concentrações utilizadas para o ensaio de CIM não foram suficientes para atestar a concentração inibitória mínima para tal bactéria. Devido a saturação da solução de água ultrapura/NPs-ZnO em concentrações acima da utilizada, esta não pode ser aumentada, em virtude de que a solução precipitaria no fundo dos micropoços, levando à um erro de procedimento e, desta forma comprometendo a análise.

Emami-Karvani e Chehrazi (2011) determinaram a concentração inibitória mínima para nanopartículas de óxido de zinco frente a $S$. aureus e E.coli e verificaram que os valores da CIM foram respectivamente de 500 e $1000 \mu \mathrm{g} \mathrm{mL}^{-1}$. Lakshmi et al. (2012) sintetizaram através de método químico nanopartículas de óxido de zinco e determinaram a CIM das mesmas para $S$. aureus e E. coli, sendo esses valores de $3000 \mu \mathrm{g} \mathrm{mL}^{-1}$ para ambas as bactérias. Essa diferença na concentração inibitória mínima pode estar associada ao tamanho das nanopartículas, sendo que quanto menor for o tamanho, maior a relação área/volume e consequentemente a atividade antimicrobiana é potencializada e, a quantidade de bactérias utilizadas na análise.

De forma análoga ao realizado para as NPs-ZnO, realizou-se o ensaio de CIM para as NPs$\mathrm{TiO}_{2}$, porém, como já mencionado, o $\mathrm{TiO}_{2}$, sem um agende externo fornecedor de luz, não apresenta atividade antimicrobiana eficaz, pois a fotoexcitação não acontece e o mecanismo inibidor fica comprometido, fato este, comprovado na presente análise. Salienta-se que, de forma semelhante ao ocorrido com as NPs-ZnO, não foi possível a utilização de uma solução mais concentrada para os testes de CIM, devido à saturação ser alcançada e ocorrer a deposição do material no fundo dos micropoços, comprometendo a análise.

Em estudo realizado por Maness et al. (1999), os autores incidiram energia luminosa sobre o $\mathrm{TiO}_{2}$ e verificaram através do teste de plaqueamento em superfície que a concentração de $\mathrm{TiO}_{2}$ que se mostrou mais eficaz para matar células de E. coli variando entre $10^{3} \mathrm{e} 10^{8} \mathrm{UFC} \mathrm{mL}^{-1}$ foi de $1 \mathrm{mg} \mathrm{mL} \mathrm{m}^{-1}$. Ainda, o estudo comprovou que concentrações de $\mathrm{TiO}_{2}$ maiores que $1 \mathrm{mg} \mathrm{mL}-1$ reduzem a eficiência de morte para bactérias $E$. coli. Tal fato pode ser justificado pela turbidez causada pela elevada concentração de partículas do $\mathrm{TiO}_{2}$ em suspensão e o baixo poder de penetração da radiação UV, o que reduz a intensidade da radiação pelo sistema.

\section{CONCLUSÃO}

Quando avaliada a atividade antimicrobiana das NPs-ZnO pelo ensaio de difusão em meio sólido verificou-se que o valor do halo médio de inibição foi de $1,1 \pm 0,06 \mathrm{~cm} \mathrm{e} 0,7 \pm 0,15 \mathrm{~cm}$ para $S$. aureus e E. coli, respectivamente. A CIM das NPs-ZnO determinada no estudo para inibir S. aureus está entre $391,7 \mu \mathrm{g} \mathrm{mL}^{-1}$ e $783,3 \mu \mathrm{g} \mathrm{mL} \mathrm{m}^{-1}$. Já para $E$. coli não foi possível determinar a 
CIM. Para as NPs-TiO 2 , não observou-se a manifestação da atividade antimicrobiana nem pelo teste de difusão em meio sólido e nem pela CIM.

O presente estudo demonstrou que as NPs-ZnO apresentam potencial aplicação para suporte em materiais cuja funcionalidade antimicrobiana deseja ser inserida. Ainda, sugere-se estudos para as $\mathrm{NPs}-\mathrm{TiO}_{2}$ fotoexcitadas, com intuito de verificar se há atividade antimicrobiana frente as bactérias testadas.

\section{AGRADECIMENTOS}

Os autores agradecem à Unochapecó pela estrutura disponibilizada para a realização deste trabalho. Agradecem também a CAPES pelo suporte financeiro e a Kher Group pelo fornecimento das nanopartículas de óxido de zinco usadas no estudo.

\section{REFERÊNCIAS}

BONILLA, A.M.; CERRADA, M.L.; FERNÁNDEZ-GARCÍA, M.; KUBACK, A.; FERRER, M.; FERNÁNDEZ-GARCÍA, M. Biodegradable polycaprolactone-titania nanocomposites: preparation, characterization and antimicrobial properties. Int. J. Mol. Sci., v. 14, p. 9249-9266, 2013.

BONILLA; A.M.; GARCÍA, M.F. Polymeric materials with antimicrobial activity. Prog. Polym. Sci., v. 37, p. 281-339, 2012.

BRAYNER, R., ILIOU, R. F., BRIVOIS, N., DJEDIAT, S., BENEDETTI, M. F., FIÉVET, F. Toxicological impact studies based on Escherichia coli bacteria in ultrafine $\mathrm{ZnO}$ nanoparticles colloidal medium. Nano Lett., v. 6, p. 866-870, 2006.

CLSI. Performance standards for antimicrobial disk susceptible tests; Approved standard Eleventh Edition. CLSI document M02-A11. Wayne, Pennsylvania: Clinical and Laboratory Standards Institute, 2012a.

CLSI. Performance standards for antimicrobial susceptibility testing. Twenty-second Informational Supplement. CLSI document M100-S22. Wayne, Pennsylvania: Clinical and Laboratory Standards Institute, 2012b.

DIZAJ, S. M., LOTFIPOUR, F., BARZEGAR-JALALI, M., ZARRINTAN, M. H., ADIBKIA, K. Antimicrobial activity of the metals and metal oxide nanoparticles. Mater. Sci. Eng. C, v. 44, p. 278-284, 2014.

EMAMI-KARVANI, Z., CHEHRAZI, P. Antibacterial activity of ZnO nanoparticle on grampositive and gram-negative bacteria. Afr. J. Microbiol. Res., v. 5, n 12, p. 1368-1373, 201.

ESPITIA, P. J. P., SOARES, N. F. F., COIMBRA, J. S. R., ANDRADE, N. J., CRUZ, R. S., 
MEDEIROS, E. A. A. Zinc oxide nanoparticles: synthesis, antimicrobial activity and food packaging applications. Food Bioprocess Tech., v. 5, p. 1447-1464, 2012.

FU, G.; VARY, P.S.; LIN, C.T. Anatase $\mathrm{TiO}_{2}$ nanocomposites for antimicrobial coatings. J. Phys. Chem. B., v. 109, p. 8889-8898. 2005.

JOO, J.; KWON, S.G.; YU, T.; CHO, M.; LEE, J.; YOON, J.; HYEON, T. Large-scale synthesis of $\mathrm{TiO}_{2}$ nanorods via nonhydrolytic sol-gel ester elimination reaction and their application to photocatalytic inactivation of E. coli. J. Phys. Chem. B, v. 109, p. 15297-15302, 2005.

KUMARI, M., KHAN, S. S., PAKRASHI, S., MUKHERJEE, A., CHANDRASEKARAN, N. Cytogenetic and genotoxic effects of zinc oxide nanoparticles on root cells of Allium cepa. J. Hazard. Mater., v. 190, p. 613-621, 2011.

LAKSHMI, J., SHARATH, R., CHANDRAPRABHA, M.N., NEELUFAR, E., HAZRA, A., PATRA, M. Synthesis, characterization and evaluation of antimicrobial activity of zinc oxide nanoparticles. J. Biochem. Tech. v. 3, n ${ }^{\circ}$ 5, p. S151-S154, 2012.

MANESS, P-C.; SMOLINSKI, S.; BLAKE, D.M.; HUANG, Z.; WOLFRUM, E.J.; JACOBY, W.A. Bactericidal activity of photocatalytic $\mathrm{TiO}_{2}$ reaction: toward an understanding of its killing mechanism. J. Appl. Microbiol., v. 65, nº 9, p. 4094-4098, 1999.

MIRZA, E. H., IBRAHIM, W. M. A. B. W., MURPHY, B. P., DJORDJEVIC, I. Polyoctanediol citrate-zinc oxide nano-composite multifunctional tissue engineering scaffolds with anti-bacterial properties. Dig. J. Nanomater. Biostruct., v. 10, p. 415-428, 2015.

NAFCHI, A.M., ALIAS, A.K., MAHMUD, S., ROBAL, M. Antimicrobial, rheological, and physicochemical properties of sago starch films filled with nanorod-rich zinc oxide. J. Food Eng., p. 511-519, 2012.

NARAYANAN, P. M., WILSON, W. S., ABRAHAM, A. T., SEVANAN, M. Synthesis, characterization and antimicrobial activity of zinc oxide nanoparticles against human pathogens. BioNanoSci., v. 2, p. 329-335, 2012.

OHIRA, T.; YAMAMOTO, O.; IIDA, Y.; NAKAGAWA, Z. Antibacterial activity of ZnO powder with crystallographic orientation. J. Mater. Sci. Mater. Med., v. 19, p. 1407-1412, 2008.

PADMAVATHY, N., VIJAYARAGHAVAN, R. Enhanced bioactivity of ZnO nanoparticles-an antimicrobial study. Sci. Technol. Adv. Mater., v. 9, p. 1-7, 2008.

RAI, M., YADAV, A., GADE, A. Silver nanoparticles as a new generation of antimicrobials. Biotechnol. Adv., v. 27, n 1, p. 76-83, 2009.

SAWAI, J. Quantitative evaluation of antibacterial activities of metallic oxide powders ( $\mathrm{ZnO}$, 
$\mathrm{MgO}$ and $\mathrm{CaO}$ ) by conductimetric assay. J. Microbiol. Methods, vol. 54, p. 177-182, 2003.

SINGH, S.; MAHALINGAM, H.; SINGH, P.K. Polymer-supported titanium dioxide photocatalysts for environmental remediation: A review. Appl. Catal., A., v. 462-463, p. 178-195, 2013.

SIRELKHATIM, A.; MAHMUD, S.; SEENI, A.; KAUS, N.H.M.; ANN, L.C.; BAKHORI, S.K.M.; HASAN, H.; MOHAMAD, D. Review on zinc oxide nanoparticles: antibacterial activity and toxicity mechanism. Nano-Micro Lett., v. 7, n 3, p. 219-242, 2015.

YAMAMOTO, O. Influence of particle size on the antibacterial activity of zinc oxide. Int. J. Inorg. Mater., v. 3, p. 643-646, 2001. 